\title{
Effect of Single-leg Half Squat Exercise on Forward Bending Test in Normal Adults
}

\author{
KAZUNORI MOROZUMI ${ }^{1)}$, IWAO YAMAMOTO ${ }^{4)}$, TAKAYUKI FUJIWARA ${ }^{4)}$, \\ TAKUYA NiSHIYA ${ }^{1)}$, TOMIHIRO ICHIKAWA ${ }^{1)}$, YOSHIE TAKEUCHI ${ }^{1)}$, \\ ChIEKO UMeKI $^{1)}$, Hiroshi KarasunO ${ }^{2)}$, NOBUyOSHI NAKAMURA ${ }^{3)}$ \\ 1) Department of Rehabilitation, Hachiohji Health Cooperative Shiroyama Hospital: \\ 3-2872-1, Motohachiohjimachi, Hachiohji, Tokyo, 193-0826 Japan. \\ TEL+81-426-65-2679 FAX+81-426-65-2679 E-mail: moroz@nifty.com \\ 2) Research Institute of Health Science and Education \\ ${ }^{3)}$ Waseda Collage of Medical Arts and Sciences \\ 4) Shinshu University
}

\begin{abstract}
We have already reported on the effect of a standing-up exercise on forward bending in the long sitting position in elderly subjects. Each subject performed forward bending before and after carrying out the standing-up exercise. The results indicated that forward bending in the long sitting position measured after the standing-up exercise improved significantly $(\mathrm{p}<0.001)$. We hypothesized that contraction of muscles surrounding the hip joints and knee joints during the standing-up exercise performed as a light load exercise had some inhibitory effects on the hamstring muscles and the muscles of the upper back and the lumbar regions. We also tested the influence of the standing-up exercise in normal adult subjects so as to verify the findings in the clinical situation. However, we failed to obtain significant effect in the normal adult subjects when the test was carried out under the same load conditions as used for the elderly subjects, although the test results showed similar tendencies to those observed in the elderly subjects. In this study, we tested the effect of a single-leg half squat exercise in normal adult subjects to determine the loading dose of the warm-up exercise required for facilitating forward bending in the long sitting position. In a control group, subjects sat at ease for 3 minutes before the forward bending test, and in a squat group, subjects performed single-leg half squatting before the test. Forward bending in the long sitting position improved significantly in the squat group compared with the control group. These results suggest that the order of training items should be considered when instructing the elderly and normal adults in health exercises and low back pain prevention exercises.
\end{abstract}

Key words: Single-leg half squat, Normal adult, Forward bending in long sitting position

(This article was submitted Aug. 15, 2003, and was accepted Sep. 29, 2003)

\section{INTRODUCTION}

Physical therapists who are working at Health Cooperative Hospitals have a diversity of roles ${ }^{1,2}$ ) in addition to the regular practice of physical therapy. One of their roles is to give the elderly guidance in maintenance of health and physical fitness, prevention and improvement of low back pain, etc ${ }^{3-10)}$. When we instruct the elderly in exercises for such purposes, we generally start with breathing exercise (abdominal respiration) or stretching of muscles and tendons, except for those who have pains due to strong contraction in muscles and/or joints, hypertonia, hematogenous disorders, etc. In the field of sports physiology and training science, there are a number of reports describing 
effectiveness of introducing an overall light-load exercise (at least 20-minute aerobic exercise including jogging) and then sufficient muscle stretching exercises before starting a muscle building exercise or a full-scale game ${ }^{12-23)}$. More specifically, the overall light-load exercise introduced as a warm-up exercise accelerates peripheral blood circulation and rise of muscle temperature, and also makes the subsequent stretching more effective.

We have already reported on the effect of a standing-up exercise as a warm-up exercise for the forward bending test in the long sitting position (an indication of flexibility) in elderly subjects ${ }^{11)}$. The forward bending (in the long sitting position) values improved significantly $(\mathrm{p}<0.001)$ when subjects performed the standing-up exercise compared with the case when they performed no standing-up exercise. Mean $( \pm \mathrm{SD})$ test values were $3.1 \pm 11.2$ $\mathrm{cm}$ after 10 times of standing-up and $3.8 \pm 11.2 \mathrm{~cm}$ after 20 times of standing-up. Mean $( \pm \mathrm{SD})$ control test value was $0.5 \pm 11.7 \mathrm{~cm}$ (see Table 1$)$. We hypothesized that contraction of muscles surrounding the hip joints and knee joints during the standing-up exercise performed as a light load exercise gave some inhibitory effects on hamstring muscles and muscles of the back and lumbar regions. Possible inhibitory effects that might have occurred included: i) reciprocal inhibition against antagonistic muscles, ii) relaxation of the hip joint extensors after the maximal contraction, and iii) improvement of preparatory state for the subsequent exercise or sports brought about by accelerated peripheral blood circulation and temperature rise in the muscles. Therefore, we reported that to introduce muscle contraction by standing-up and the like before instructing the elderly in health exercise and low back pain preventive exercise, makes the subsequent stretching exercise more effective. Further, we tested the effect of the standing-up exercise in normal adult subjects so as to verify in the clinical situation the data obtained for the elderly subjects. A similar tendency to that in the elderly subjects was also observed in the normal adult subjects. However, no significant effect was observed in them under the same load conditions as used in the elderly subjects. We considered that the difference in the test results between these two subject groups is due to the influence of aging, a process of deterioration in all aspects of mental functions and body functions in
Table 1. Mean values of Maximal Forward Bending in the Long sitting Position in elderly subjects

\begin{tabular}{ll}
\hline Control & $0.5 \mathrm{~cm} \pm 11.7$ \\
After 10 times standing-up & $3.1 \mathrm{~cm} \pm 11.2$ \\
After 20 times standing-up & $3.8 \mathrm{~cm} \pm 11.2$
\end{tabular}

$\mathrm{p}<0.001$ control and after 10 times standing-up. Not significant after 10 times standing-up and after 20 times. $\mathrm{p}<0.001$ control and after 20 times standing-up.

the elderly rather than to the characteristics specific to normal adults ${ }^{31,32)}$.

In this study, we tested the effect of the single-leg half squat exercise so as to find out the loading dose of the warm-up exercise influencing the subsequent forward bending in the long sitting position in normal adult subjects. We also discuss and report on the possibility that it is more effective to interpose a light squatting or standing-up exercise between respiration control training and stretching, when we instruct patients in health exercise or low back pain preventive exercise rather than to introduce stretching immediately after the respiration control training.

\section{METHOD}

\section{Subject}

Normal adult subjects $(n=26)$ were randomly allocated to two groups:

A: Squat group consisting of 13 subjects $(7$ males, mean age: 25.1 , mean body weight: $65.8 \mathrm{~kg}$, mean height: $171.0 \mathrm{~cm}$; 6 females, mean age: 24.6 , mean body weight: $49.7 \mathrm{~kg}$, mean height: $158.3 \mathrm{~cm}$ ); and

B: Control group consisting of 13 subjects ( 3 males, mean age 23.3, mean body weight: $63.8 \mathrm{~kg}$; mean height: $170.3 \mathrm{~cm}$; 10 females, mean age 20.5, mean body weight $53.8 \mathrm{~kg}$, mean height: $159.7 \mathrm{~cm}$ ).

The subjects of both groups were allowed to perform the following trials respectively.

\section{Procedures}

\section{A: Squat group}

Each subject performed forward bending in the long sitting position before and after single-leg squatting (20 times/leg; knee joint angle between $0^{\circ}$ and $45^{\circ}$ ) while monitored with an electric goniometer (MP Japan Co., Ltd., Tokyo Japan). The subject was allowed to control the knee joint angle by looking at a monitor placed in front of the subject so that the waveform of the goniometer 


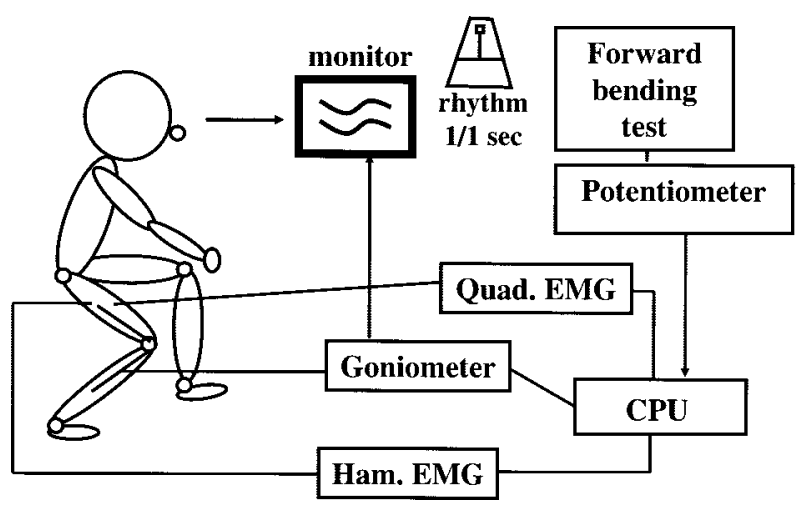

Fig. 1. Block diagram of experiment. Load dose was adjusted (once/ $1 \mathrm{sec}$.) by metronomically controlling the squat exercise.

reciprocated between the target $0^{\circ}$ line and the $45^{\circ}$ line. The rate of the squat exercise (a squat $/ \mathrm{sec}$.) was regulated with a metronome to adjust the load dose (Fig. 1).

B: Control group

Each subject performed forward bending before and after sitting at rest for 3 minutes.

\section{Measuring Method}

Each subject was seated in the long sitting position in front of a measuring instrument for the forward bending test with the hip joints and the knee joints fixed at $90^{\circ}$ and at the terminal extension position, respectively. The upper limbs were placed on $30 \mathrm{~cm}$-high tables with the elbow joints extended fully, and the positions of the third finger tips were calibrated as 0 positions. The distance of the finger tip from the 0 position when the trunk was at the maximal bending position was measured three times (Fig. 2). The maximum measured value out of three was taken as the test value, and the values obtained before and after the test were subjected to the paired t-test.

\section{RESULTS}

(1) Mean maximum forward bending test values in the squat group were $36.1 \mathrm{~cm}$ (before squatting) and $38.8 \mathrm{~cm}$ (after squatting), showing a significant increase ( $\mathrm{p}<0.01$, paired t-test) as shown in Table 2 .

(2) Mean maximum forward bending test values in the control group were $38.7 \mathrm{~cm}$ (before sitting at ease) and $39.0 \mathrm{~cm}$ (after sitting at ease), showing no significant difference between these two values (see

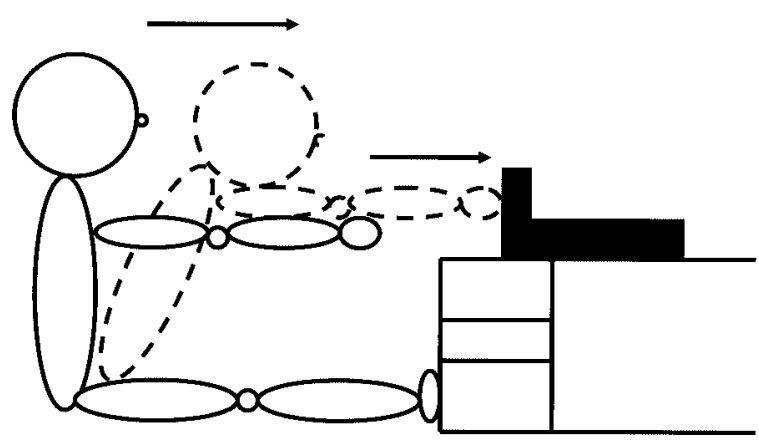

Fig. 2. Measurement of forward bending with long sitting position. The subject bent the trunk to the maximal bending position with the ankle joints and the knee joints fixed at $0^{\circ}$-position and at the terminal extension position respectively.

Table 2. Mean and SD in each group $(\mathrm{cm})$

\begin{tabular}{lcc}
\hline & befor & after \\
\hline Squat Group & $36.1 \pm 8.5$ & $38.8 \pm 7.9^{*}$ \\
Control Group & $38.7 \pm 7.9$ & $39.0 \pm 8.1$ \\
\hline
\end{tabular}

$*: \mathrm{p}<0.01$.

Table 2).

(3) Comparison between the squat group and the control group was made in terms of the maximum forward bending values in the long sitting position minus the forward bending values before the trials in the respective groups. The mean difference in the squat group was $2.7 \mathrm{~cm}$, whereas that in the control group was 0.3. Thus, the squat group showed a significant increase $(\mathrm{p}<0.01$, nonpaired t-test).

\section{DISCUSSION}

While no significant difference was observed between the maximum forward bending test values in the long sitting position measured before and after the trial respectively, the test values increased significantly after the trial in the squat group. We hypothesized that contraction of muscles surrounding the hip joints and knee joints during the single-leg half squat exercise gave some inhibitory effects on hamstring muscles and muscles of the back and lumbar regions. Possible inhibitory effects are: i) reciprocal inhibition, ii) relaxation of the hip joint extensors after the maximal contraction, and iii) improvement of preparatory state for the subsequent exercise brought about by 
accelerated peripheral blood circulation and temperature rise in the muscles, similar to the effects of the standing-up exercise in the elderly.

\section{i) Reciprocal inhibition}

Satoh et al. ${ }^{28)}$ report that the setting of quadriceps femoris muscles influences the finger-to-floor distance and that it is possibly due to the influence of reciprocal inhibition against antagonistic muscles occurring with contraction of agonistic muscles. There are prior studies made by Etnyre et al. ${ }^{24)}$ and Roberts et al. ${ }^{25)}$, and they resorted to either static contraction or dynamic contraction. The single-leg half squat exercise we employed in our study is performed mainly by quadriceps femoris muscles which repeat alternately shortening contraction when the knees are extended and extending contraction when the knees are bended. We consider that the repeated contractions of quadriceps femoris muscles might have brought about influence of reciprocal inhibition on the antagonist hamstring muscles.

\section{ii) Relaxation after maximal contraction of agonistic muscles}

Yoshizaki et al. ${ }^{29)}$ report on relaxation of hip joint extensors after maximal contraction as follows: Tendons are stretched by shortening of muscle fibers as a result of isometric contraction of the muscles that are going to extend at around their maximal extension positions, and thus the range of motion is increased. Meanwhile, activation of the majority of motor neurons caused by the maximal isometric contraction lowers the excitability in the spinal cord motor neuron pool. This inhibits the subsequent defensive stretch reflex enabling extension of the muscles. However, we consider that there was little possibility that nearly maximal contraction occurred in the hamstring muscles and gluteal muscles during the half squat exercise in our study. Ichihasi et al. ${ }^{30)}$ report, in kinetic analyses of leg extending movement in a closed kinetic chain, that the activities of not only quadriceps femoris muscles but also hamstring muscles are involved in the terminal extension of the knee joint. The singleleg half squatting we employed in our study is a movement of a closed kinetic chain. It is very likely here that the activities of the quadriceps femoris muscles and simultaneous contraction of the hamstring muscles (as agonistic muscles if they are to be stretched) during single-leg half squatting induced relaxation of the muscles surrounding the hip and knee joints. Condon et al. ${ }^{26)}$ and Ostering et al. ${ }^{27)}$ also reported on the usefulness of relaxation resorting to contraction of agonistic muscles.

\section{iii) Acceleration of peripheral blood circulation and muscle temperature rise}

Aoki et al. ${ }^{12)}$ stated that a rise in muscle temperature and body temperature occurring with muscle contraction improves many physiological functions and is closely related to motor performance.

Akutsu $^{13)}$ reported on the effects of warm-up exercises. He stated that increase of muscle temperature is involved in changes in physical properties of muscles including viscosity and elasticity, reduction of tension in antagonistic muscles and the range of motion in joints to influence flexibility and extensibility of the body.

There are many other reports on warming up ${ }^{14-23)}$.

In our study, we expected influences similar to those as described in these reports.

\section{CONCLUSION}

The single-leg half squat exercise exhibited effects on forward bending in the long sitting position in normal adult subjects. The test values of forward bending in the long sitting position improved significantly after the squat exercise.

This result clarifies some of the load dose of warm-up exercises which influence forward bending in the long sitting position in normal adults. The load dose was quite different from the optimum dose for the elderly subjects. We believe that, when the elderly and ordinary persons are instructed in health exercise and low back pain preventive exercise, it makes the subsequent stretching exercise more effective to introduce beforehand musculation including standing-up or light squatting. We intend to collect more clinical data to elucidate the mechanism, and to make more detailed studies on optimum load dose.

\section{REFERENCE}

1) Health Co-Operative Association of JCCU: Patients' Bill of Rights, Japan, 1991.

2) Health Co-Operative Association of JCCU: Working Committee, Ideal Medical Treatment and Nursing Care for the Elderly that Health Co-Op can Offer, 
2002.

3) Naitoh H, Kogure I, Aoki J: Relationship between low back pain and values of forward bending test in long sitting position in the elderly. Rep Res Center for Physical Education, 1997, 25: 175-179.

4) Kenney WL: American College of Sports Medicine. In: Physical Fitness Testing, ACSM's Guidelines for Exercise, Testing and Prescription, 5th ed., Philadelphia Media: Williams and Wilkins, 1995, pp 49-85.

5) Aoki J: Physical fitness test items in terms of healthrelated physical fitness test. J J Sports Sci, 1993, 12: 605-608.

6) Battie MC, Bigos SJ, Fisher LD, et al.: The role of spinal flexibility in back pain complaints within industry. Spine, 1990, 15: 768-773.

7) Sawada T, Suzuki H, Shimada N, et al.: Physical fitness and low back pain in housewives. J Clin Sports Medicine, 1986, 3: 925-930.

8) Suzuki H, Sawada T, Niremoto T, et al.: Physical fitness and locomotor disability in housewives. J Clin Sports Medicine, 1988, 5: 797-801.

9) Kobayashi H: Feature article, Exercise for the elderly - physical fitness of the elderly. Health Care, 1991, 33 (12): 833-838.

10) Shibata H: Feature article, The elderly and science of physical exercise - measurement of physical fitness in the elderly and evaluation. J Health, Physical Education and Recreation, 1987, 37: 658-661.

11) Morozumi K, Fujiwara $T$, Yamamoto I, et al.: Effect of previous standing-up exercise on forward bending test in the elderly. J Phys Ther Sci, 2003, 15: 39-45.

12) Aoki J, Satoh Y, Muraoka I: Physiology of warm-up and cooling-down. In: Sport Physiology, Basics of Sport Physiology.1st.ed., Tokyo: Ichimura Publishing House, 2001, pp 41-49.

13) Akutsu K: Physiology of Warm-up. J Phy Ed, 1959, 7 (3): 46-49.

14) Ishikawa T: Physiology of Warm-up. Research $J$ of Phy Ed, 1973, 18: 1-8.

15) Stewart IB, Sleivert GG: The effect of warm-up intensity on range of motion and anaerobic performance. J Orthop Sports Phys, 1998, 27: 154161.

16) Kitada K, Tamaki H, Kawahara $S$, et al.: Effect of warm-up with bicycle ergometer on quick exhibition of muscle force by upper limbs. J Training Science, 2000, 12 (2): 111-130.

17) Suzuki T, Nemoto I, Nakamura N, et al.: Effect of resistance training as warm-up exercise on enduring performance and result of competition. J Training Science, 1999, 11 (2): 43-50.
18) Green JP, Grenier SG, Mcgill SM: Low-back stiffness is altered with warm-up and bench rest: Implications for athletes. Med Sci Sports Exerc, 2002, 34 (7): 10761081.

19) Grodjinovsky A, Magel JR: Effect of warm-up on running performance. Res Quart, 1970, 41: 116-119.

20) Katamoto S: Physiology of warm-up, Jpn J Sports Sci, 1988, 7 (10): 620-627.

21) Gotoh S, Ikegami H: Effect of warm-up on dynamic state of blood lactic acid during exercise. Jpn J Phys Fitness Sports Med, 1987, 36: 78-84.

22) Hatta H: Relationship between production/removal of lactic acid and LT. J Clin Sports Medicine, 1992, 9 (7): 745-750.

23) Suzuki T, Nemoto I, Nakamura N, et al.: Effect of resistance training by initial motion loading on range of motion in joints. HIRO-KYUYO (Science of Fatigue and Rest), 1999, 14 (1): 69-84.

24) Etnyre BE, Abraham LD: H-reflex changes during static stretching and two variations of proprioceptive neuromuscular facilitation techniques. Electroencephalogr Clin. Neurophysiol., 1986, 63: 174-179.

25) Roberts JM, Wilson K: Effect of stretching duration on active and passive range of motion in the lower extremity. Br J Sports Med, 1999, 33: 259-263.

26) Condon SM, Hutton RS: Soleus muscle electromyographic activity and ankle dorsiflexion range of motion during four stretching procedures. Phys Ther, 1987, 67 (1): 24-30.

27) Osternig LR, Robertson RN, Troxel RK, et al.: Differential responses to proprioceptive neuromuscular facilitation (PNF) stretch techniques. Med Sci Sports Exerc, 1990, 22 (1): 106-111.

28) Satoh H, Takahasi T, Yamamoto Y, et al.: Effect of setting of quadriceps on changes in finger-to-floor distance. Journal of TOKYO PHYSICAL THERAPY CHAPTER of JPTA, 2000, 14: 20-22.

29) Yoshizaki K, Simosaka M, Fujiwara $T$, et al.: Relaxation of hip joint extensors after maximal contraction. J Jpn Physical Therapy Association, 1993, 20 (Institutionary Special Issue), 34 (in Japanese).

30) Ichihashi N, Hidaka M, Urano Y, et al.: Kinesiological analysis of static leg extension and knee extension. J Jpn Physical Therapy Association, 1997, 24 (6): 341346.

31) Kameyama M: Geriatric gerontology in future. Jpn J Geriatr, 1989, 26: 1-9.

32) Shephard RJ: Translated by Harada M \& Yamaji K: Shephard's gerontology - motor performance and aging. 1st Ed., 2nd print, Tokyo: IGAKU SHOIN, Ltd., 1982, pp 40-118. 